\title{
New Photocurable Acrylic/Silsesquioxane Hybrid Optical Materials: Synthesis, Properties, and Patterning
}

\author{
Hung-Wen Su, Wen-Chang Chen,* Wen-Chin Lee, Jinn-Shing King
}

Synthesis, properties, and patterning of new acrylic/silsesquioxane hybrid materials are reported. PMA-functionalized PHSSO was synthesized by hydrosilylation and then formulated with acrylate monomer mixtures to yield the photocurable materials. Experiments suggest that the thermal/mechanical properties of the parent acrylic polymers could be significantly enhanced by incorporating nano-sized silsesquioxane moieties. The refractive index and optical loss were reduced by increasing the silsesquioxane content. The hybrid materials could be photocured and developed a Y-shape channel pattern; potential applications include uses in patterned electronic and optoelectronic devices.

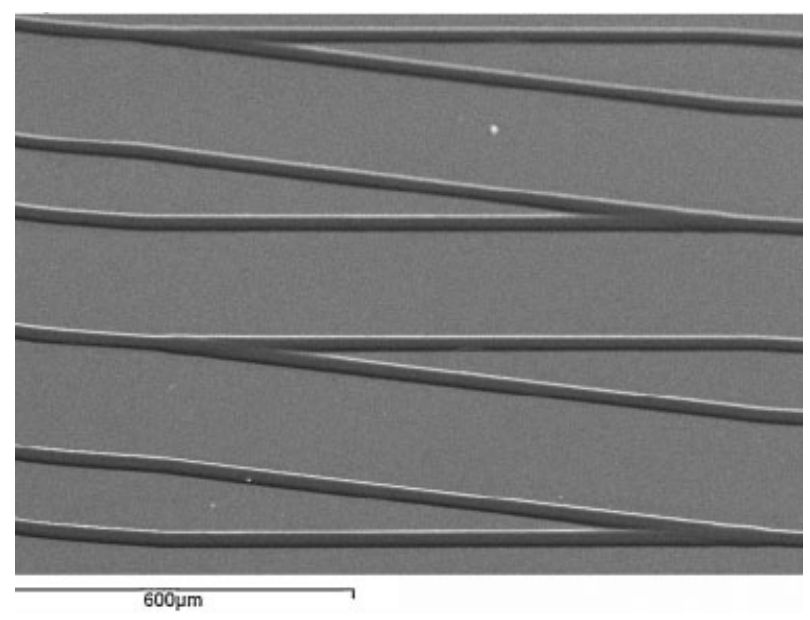

\section{Introduction}

Organic/inorganic hybrid materials have been recognized as a new class of advanced materials because of the versatile synthetic approaches and molecular tailing properties. ${ }^{[1-5]}$ Polysilsesquioxanes and their hybrid materials have attracted extensive research interest because of their excellent thermal, mechanical, electronic, and optical

H.-W. Su, W.-C. Chen

Institute of Polymer Science and Engineering, National Taiwan University, Taipei 106, Taiwan

Fax: +88622362 3040; E-mail: chenwc@ntu.edu.tw H.-W. Su

AGI corporation, Taipei 492, Taiwan

W.-C. Chen

Department of Chemical Engineering, National Taiwan University, Taipei 106 Taiwan

W.-C. Lee, J.-S. King

Industrial Technology Research Institute, Hsinchu 300, Taiwan properties. ${ }^{[6]}$ The silsesquioxane functionality employed for preparing the hybrid materials include acrylic, ${ }^{[7]}$ epoxy, ${ }^{[8-13]}$ amine, ${ }^{[14-16]}$ vinyl, ${ }^{[17]}$ hydrido, ${ }^{[17]}$ isocyanate, ${ }^{[18]}$ halide, ${ }^{[19]}$ and norbonyl. ${ }^{[20]}$

Extensive studies have been reported on silsesquioxane-based polymeric materials for electronic and optoelectronic applications, such as low dielectric constant materials, ${ }^{[21]}$ optical waveguides, ${ }^{[22]}$ or light-emitting diodes. ${ }^{[23]}$ Linear optical planar waveguides fabricated from poly(phenyl silsesquioxane)(PPSSO), ${ }^{[22 a]}$ oligomeric methylsilsesquioxane-titania, ${ }^{[22 b]}$ and phenylsilsesquioxanetitania $^{[22 c]}$ materials have shown high thermal stability, surface planarity, and excellent optical transparence. Although such materials show excellent optical and thermal properties, the flexibility is relatively poor due to their high inorganic content and thus limits their applications for flexible electronic and optoelectronic devices. Besides, extra-complicated lithographic processes are required to pattern the above materials into devices 

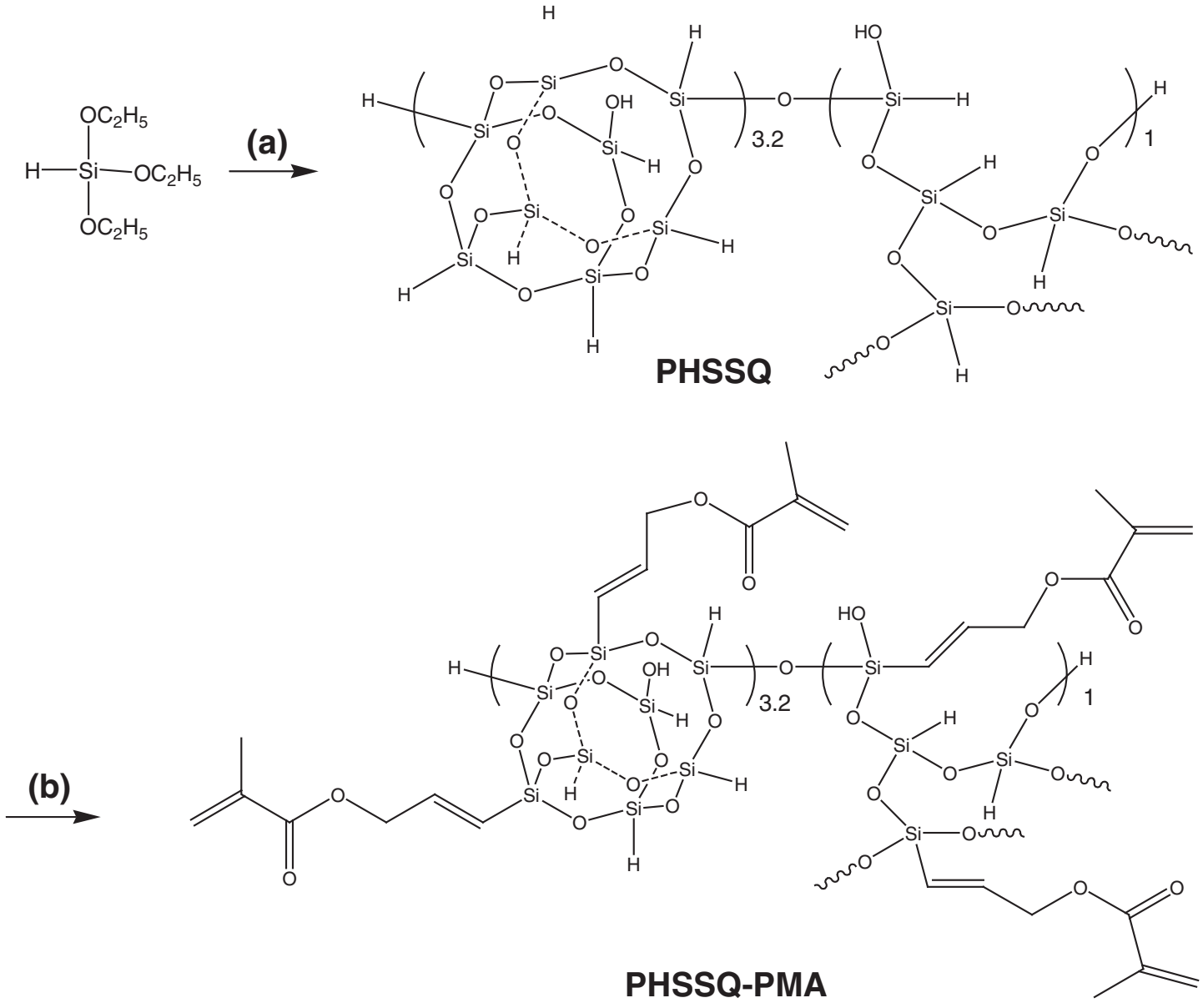

(c)

\section{Photocurable composition}

Spin coating

\section{Photo-patterning}

Scheme 1. Reaction scheme for preparing photosensitive PHSSO-PMA, its photocurable compositions, and patterned devices. (a) Reaction condition: acid catalyzed reaction at $60^{\circ} \mathrm{C}$ for $3 \mathrm{~h}$, (b) hydrosilylation reaction of PHSSO with PMA using Pt(dcp) at $80^{\circ} \mathrm{C}$ for $5 \mathrm{~h}$, and (c) formulation with acrylate monomer mixtures and photoinitiator.

since they require additional photoresists for patterning. Therefore, the development of photosensitive silsesquioxane hybrid materials is very important for their applications in electronic and optoelectronic devices. ${ }^{[24]}$

In this study, synthesis and characterization of new photocurable silsesquioxane/acrylic hybrid optical materials are reported. Poly(hydrogen silsesquioxanes) (PHSSO) precursor solution was first prepared through the hydrolysis and condensation of triethoxysilane (TES) in the mix solvents of methyl isobutyl ketone (MIBK) and tetrahydrofuran (THF). Then, propargyl methacrylate (PMA) was incorporated with PHSSO via Pt-catalyzed hydrosilylation to obtain the methacryloyl-functionalized PHSSO-PMA, as shown in Scheme 1. Three photocurable materials were prepared by different compositions of the PHSSO-PMA with methacrylate monomers of benzyl methacrylate
(BzMA), bisphenol A ethoxylate diacrylate (BAEDA), and trimethylolpropane triacrylate(TMPTA)/BzMA (w/w, $80: 20)$, respectively. The above three kinds of hybrid materials depending on their compositions are named as P1-0-P1-75, P2-0-P2-40, and P3-0-P3-40, respectively, as shown in Table 1 . Then, photoinitiator of bis(2,4,6trimethylbenzoyl)-phenylphosphineoxide (IRGA819) was added to the above precursor solution followed by spin-coating and photolithographic process to form patterned devices. The thermomechanical properties of the prepared hybrid materials were characterized by thermogravimetric analysis (TGA) and thermomechanical analysis (TMA). The surface structure of the prepared films was characterized by atomic force microscopy (AFM) and scanning electron microscopy (SEM). The optical characteristics of the prepared hybrid optical films were charac- 
Table 1. Composition and properties of the prepared hybrid materials.

\begin{tabular}{|c|c|c|c|c|c|c|c|}
\hline \multirow[t]{2}{*}{$\begin{array}{l}\text { PHSSO-PMA/ } \\
\text { acrylate mixture }\end{array}$} & Ratio & \multirow[t]{2}{*}{$\begin{array}{l}\text { Refractive index } \\
\text { at } 1310 \mathrm{~nm}\end{array}$} & \multirow{2}{*}{$\frac{\begin{array}{c}\text { Film } \\
\text { thickness }\end{array}}{\mu \mathrm{m}}$} & \multirow{2}{*}{$\begin{array}{l}T_{\mathrm{d}}^{\mathrm{a})} \\
\frac{{ }^{\circ} \mathrm{C}}{}\end{array}$} & \multirow{2}{*}{$\begin{array}{c}\begin{array}{c}\text { Residue at } \\
\left(800^{\circ} \mathrm{C}\right)\end{array} \\
\text { wt.-\% }\end{array}$} & \multirow{2}{*}{$\frac{\mathrm{CTE}}{\mathrm{ppm} \cdot{ }^{\circ} \mathrm{C}^{-1}}$} & \multirow{2}{*}{$\begin{array}{l}\begin{array}{c}\text { Optical } \\
\text { loss }\end{array} \\
\mathrm{dB} \cdot \mathrm{cm}^{-1}\end{array}$} \\
\hline & wt.-\% & & & & & & \\
\hline \multirow[t]{5}{*}{ PHSSO-PMA/BzMA } & $0: 100(\mathbf{P 1}-\mathbf{0})$ & $-b)$ & $-b)$ & 224 & 1.2 & $-{ }^{b)}$ & $-{ }^{c)}$ \\
\hline & 10:100 (P1-10) & -b) & 1.03 & 232 & 5.1 & 322 & -c) \\
\hline & $30: 100$ (P1-30) & $-b)$ & 1.54 & 238 & 12.5 & 222 & $-c)$ \\
\hline & 50:100 (P1-50) & $-b)$ & 1.62 & 241 & 19.1 & 177 & $-{ }^{c)}$ \\
\hline & 75:100 (P1-75) & $-{ }^{b)}$ & 1.75 & 242 & 24.3 & 121 & $-{ }^{c)}$ \\
\hline \multirow[t]{5}{*}{ PHSSO-PMA/BAEDA } & $0: 100$ (P2-0) & 1.561 & 11.36 & 408 & 6.8 & 151 & 0.68 \\
\hline & 10:100 (P2-10) & 1.557 & 12.74 & 403 & 15.1 & 134 & $-{ }^{d)}$ \\
\hline & 20:100 (P2-20) & 1.552 & 13.55 & 411 & 19.2 & 121 & 1.19 \\
\hline & $30: 100$ (P2-30) & 1.547 & 13.81 & 418 & 23.7 & 118 & 0.74 \\
\hline & 40:100 (P2-40) & 1.536 & 14.31 & 427 & 29.8 & 105 & 0.43 \\
\hline \multirow[t]{5}{*}{ PHSSO-PMA/TMPTA-BzMA } & $0: 100$ (P3-0) & 1.508 & 7.68 & 410 & 3.6 & 128 & 0.58 \\
\hline & 10:100 (P3-10) & 1.500 & 8.34 & 412 & 10.4 & 115 & 0.51 \\
\hline & 20:100 (P3-20) & 1.498 & 8.65 & 416 & 14.5 & 103 & 0.42 \\
\hline & $30: 100$ (P3-30) & 1.496 & 10.47 & 425 & 17.4 & 76 & 0.31 \\
\hline & 40:100 (P3-40) & 1.494 & 11.35 & 430 & 21.1 & 67 & 0.29 \\
\hline
\end{tabular}

a) Determined from the intercept of the two tangent lines of the TGA curves; ${ }^{\text {b) }}$ The film by spin coating is too thin to measure its refractive index; ${ }^{c}$ The thickness is too thin for optical waveguide measurement; ${ }^{\mathrm{d})}$ The film quality is not enough for the optical loss measurement.

terized by their optical transparence, refractive index, and optical loss. It was found that Y-shaped patterned devices with $10 \mu \mathrm{m}$ line width, $1.5 \mu \mathrm{m}$ thickness, and a splitting angle of $10^{\circ}$ could be achieved from the PHSSO-PMA/ acrylic hybrid materials.

\section{Experimental Part}

\section{Materials}

Triethoxysilane (TES; 95\%; TCI, Japan), propargyl methacrylate (PMA; 98\%; Lancaster, UK), dichloro(dicyclopentadienyl) platinum (II) [Pt(dcp); 99\%; Strem, USA] were used without further purification. BzMA (96\%; Aldrich, USA), bisphenol A ethoxylate (1.5EO/phenol) diacrylate (BAEDA, Aldrich, USA), TMPTA (technical grade; Aldrich, USA), hydrochloric acid ( $\mathrm{HCl} ; 37 \%$; Scharlau Chemie, Spain), IRGA819 (CIBA, USA) were used as received. Poly(methyl silsesquioxane) (PMSSO; $\bar{M}_{\mathrm{W}}=7000-8000$, average $\mathrm{OH}$ content $=5 \%$, Gelest) was used as a reference in obtaining the approximate content of $\mathrm{Si}-\mathrm{OH}$ in the synthesized PHSSO.
Briefly, $30 \mathrm{~mL}$ of MIBK, $15 \mathrm{~mL}$ of THF, and $9.86 \mathrm{~g}$ of TES (0.06 mol) were added into a $100 \mathrm{~mL}$ three-necked round bottom flask equipped with a condenser and a dean-stark trap. With the reaction conditions of $\mathrm{pH}=1$ and $\mathrm{R}\left(\mathrm{H}_{2} \mathrm{O} / \mathrm{TES}\right)=1.5$, an aqueous solution containing $1.62 \mathrm{~g}(0.09 \mathrm{~mol})$ of deionized water and $0.058 \mathrm{~g}\left(5.6 \times 10^{-4} \mathrm{~mol}\right)$ of $\mathrm{HCl}$ was added dropwise over a period of 10 min into the flask with rigorous stirring. The equipment was then immersed in silicon oil at $60^{\circ} \mathrm{C}$. The hydrolysis and condensation reaction lasted for $3 \mathrm{~h}$ under nitrogen atmosphere. The reactive temperature was then increased to $90^{\circ} \mathrm{C}$ for another $2 \mathrm{~h}$ to remove the THF and the PHSSO precursor solution was obtained. The synthesis of PHSSQ-PMA used a reaction similar to that of single silsesquioxane cage, reported previously in the literature $^{[7 b]}$ although the present study was focused on the polymeric silsesquioxane materials with both cage-like and network-like moieties. In the following, the reaction temperature was decreased to $80{ }^{\circ} \mathrm{C}$, then $5.96 \mathrm{~g}$ of PMA $(0.048 \mathrm{~mol})$ and $80 \mathrm{mg}$ $\mathrm{Pt}(\mathrm{dcp})$ were added into the flask. Upon the completion of addition, the mixture was allowed to react for another $5 \mathrm{~h}$ and then cooled down to the room temperature to obtain the homogenous solution of PHSSO-PMA.

\section{Synthesis of PHSSO-PMA}

The PHSSO precursor was synthesized using the method reported previously by our laboratory and described briefly as below. ${ }^{[21 g]}$

\section{Photocuring and Patterning of PHSSO-PMA}

The photocurable materials were prepared by mixing PHSSO-PMA with three kinds of acrylic monomers [BzMA, BAEDA, BzMA/ 
TMPTA (80:20 wt.-\%)] with different compositions, as shown in Table 1. IRGACURE819 was used as the photoinitiator due to its outstanding absorption properties and minimum yellowing after the exposure to sufficient amounts of UV radiation. The amount of photoinitiator was 2 wt.-\% of the total solid content. By using PHSSO-PMA/TMPTA-BzMA = 40:100 (P3-40) as an example, $2.5 \mathrm{~g}$ of PHSSO-PMA in MIBK solution (the solid weight of PHSSO-PMA was about $0.5 \mathrm{~g}$ ) was mixed with $1 \mathrm{~g}$ of TMPTA, $0.25 \mathrm{~g}$ of BzMA, and $0.035 \mathrm{~g}$ of IRGA819. Then the solution was mixed by rigorously stirring for $1 \mathrm{~h}$, filtered through $0.45 \mu \mathrm{m}$ polytetrafluoroethylene membrane filter, and then spin-coated onto the split silicon wafer or $10 \times 10 \times 0.7 \mathrm{~cm}^{3}$ sheet glass at $750 \mathrm{rpm}$ for $10 \mathrm{~s}$ and soft-baked at $80^{\circ} \mathrm{C}$ for $1 \mathrm{~min}$, followed by exposure to the UV light of $365 \mathrm{~nm}$ (I-line) through a transparent mask or the predefined Cr mask with the dose of $1000 \mathrm{~mJ} \cdot \mathrm{cm}^{-2}$. Subsequently, the exposed films were developed by the mixture of MIBK/ethanol in a weight ratio of $60: 40$. A final thermal treatment was carried out at $150^{\circ} \mathrm{C}$ for $10 \mathrm{~min}$ and $220^{\circ} \mathrm{C}$ for $20 \mathrm{~min}$, respectively, to obtain the patterned optical waveguides.

\section{Characterization}

FTIR spectra of the materials on the doubly polished silicon wafers were obtained with a Perkin Elmer PARAGON 1000. Gel permeation chromatography (GPC) analysis was performed on Waters GPC system consisting of, Waters 2414 RI detector, Shodex columns (KF-802,803,805), Waters 717 plus auto-sampler, and Waters 515 HPLC pump. The system was calibrated using polystyrene standards. THF was used as the eluent, at a flow rate of $1.0 \mathrm{~mL} \mathrm{~min}^{-1}$.

Thermogravimetric analysis and DSC thermal analyses were conducted on a Perkin-Elmer Pyris 1 TGA and a TA Q100 with a refrigerated cooling system, respectively. Both measurements were performed under continuous flow nitrogen, at a heating rate of $10^{\circ} \mathrm{C} \cdot \mathrm{min}^{-1}$. A Perkin-Elmer Pyris DMA7e was used to characterize the coefficient of thermal expansion (CTE) at a heating rate of $10^{\circ} \mathrm{C} \cdot \mathrm{min}^{-1}$ from room temperature to $200^{\circ} \mathrm{C}$ under nitrogen atmosphere. A Model DI 5000 AFM was used to probe the surface morphology of the coated films. The SEM images of the lithographic patterns were obtained by a JEOL JSM-5310 microscope.

A prism coupler (Metricon Model 2100) was used to measure the film thickness and refractive index of the prepared thin films at the wavelength of $1310 \mathrm{~nm}$. The planar waveguides were fabricated with the structures of negative waveguide resisting thin films on top of a thermal oxide (refractive index $=1.447$ ) using silicon wafers as the substrate. The propagation optical losses of the prepared planar waveguides at the wavelength of $1310 \mathrm{~nm}$ were measured by a cut-back method according to our previous report. ${ }^{[22 b, 22 c]}$ The incident light beam was introduced into the $50 \mathrm{~mm}$ long straight waveguide and the output beam power intensity was measured. The waveguide was cut by $10 \mathrm{~mm}$, while the propagation loss was measured based on the difference between the input and the output light intensities using an optical power meter. For measuring the NIR absorption spectra of the prepared hybrid materials, a sample with a thickness of a few millimeters was obtained by evaporating the precursor solution in a Teflon disk under vacuum. The NIR absorption spectra were obtained using a UV-vis-NIR spectrophotometer (Jasco, model $\mathrm{V}-570$ ) in the wavelength range of 1000-2 $000 \mathrm{~nm}$ and normalized by dividing with film thickness.

\section{Results and Discussion}

\section{Polymer Structure Characterization of PHSSO-PMA and its Hybrids}

Figure 1 shows the FTIR absorption spectra of the PHSSO, PHSSO-PMA, P1-30, P2-30, and P3-30, respectively. In the PHSSO spectra, the absorption peaks at 1128 and $1072 \mathrm{~cm}^{-1}$ are attributed to the $\mathrm{Si}-\mathrm{O}-\mathrm{Si}$ stretching band of cage-like and network-like structure, respectively. ${ }^{[21 g, 22 b]}$ The ratio of cage-like/network-like is about 3.2 by curve fitting of the IR spectra in the range of $1250-950 \mathrm{~cm}^{-1}$ under the assumption of two Gaussian peaks at 1128 and $1072 \mathrm{~cm}^{-1}$. The $\mathrm{Si}-\mathrm{OH}$ content is determined by integrating the peak areas at 1300-1000 and $930-900 \mathrm{~cm}^{-1}$, which are assigned to the $\mathrm{Si}-\mathrm{O}-\mathrm{Si}$ and $\mathrm{Si}-\mathrm{OH}$ groups, respectively. By a comparison with a reference PMSSO sample from Gelest with a reported $5 \% \mathrm{OH}$ content, the approximate content of $\mathrm{Si}-\mathrm{OH}$ is about $2.3 \%$. The peak around 2255 and $829-864 \mathrm{~cm}^{-1}$ are assigned to the $\mathrm{Si}-\mathrm{H}$ stretching and $\mathrm{H}-\mathrm{Si}-\mathrm{O}$ hybrid vibration, respectively. After hydrosilylation, the peak intensity of the $\mathrm{Si}-\mathrm{H}$ bands at 830 and $2255 \mathrm{~cm}^{-1}$ decreases significantly, which suggests that the $\mathrm{Si}-\mathrm{H}$ have reacted with the propargyl group of PMA. Moreover, the methacrylate group peaks: around $2900\left(-\mathrm{CH}_{3}\right), 1720(\mathrm{C}=\mathrm{O})$, and $1640 \mathrm{~cm}^{-1}(\mathrm{C}=\mathrm{C})$ are

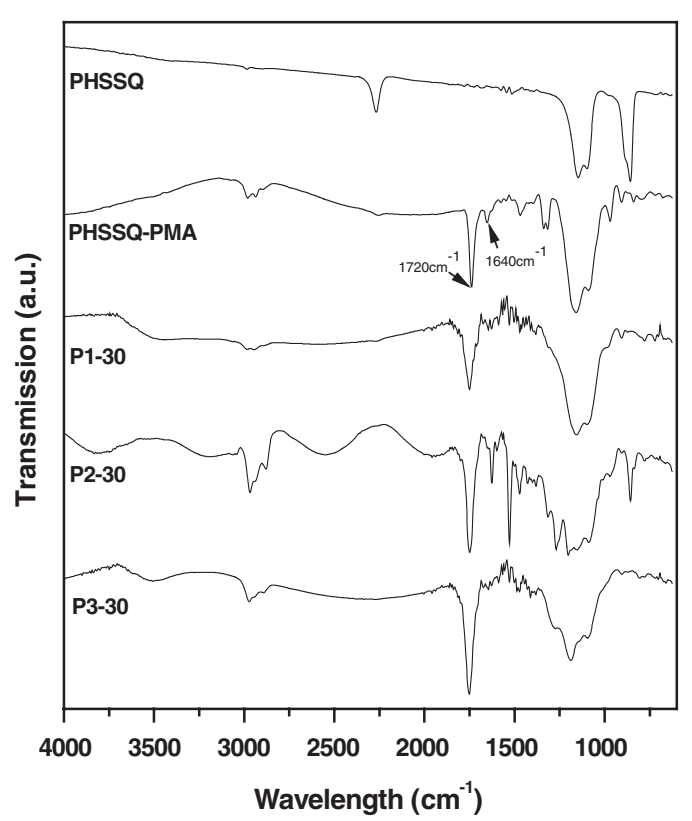

Figure 1. FTIR transmittance spectra of PHSSO, PHSSO-PMA P1-30, P2-30, and P3-30 on doubly polished silicon wafers. 


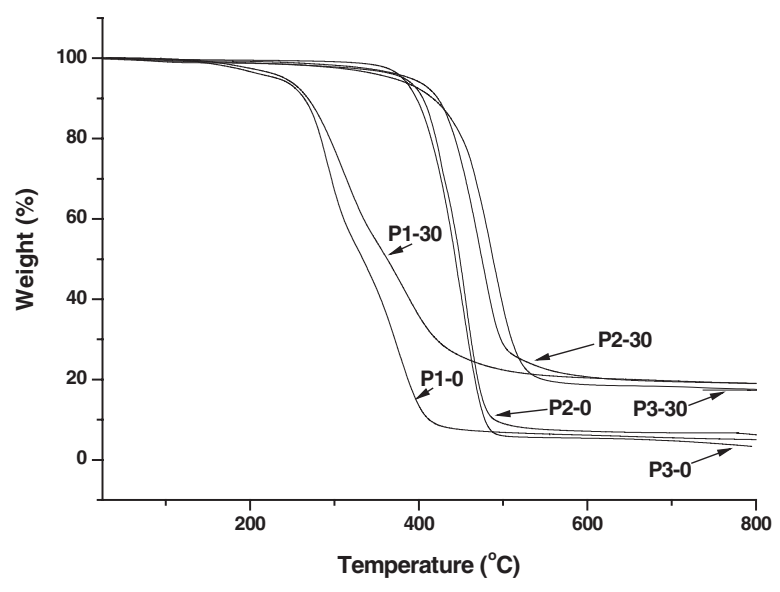

Figure 2. TGA curves of P1-0, P1-30, P2-0, P2-30, P3-0, and P3-30 at a heating rate of $10^{\circ} \mathrm{C} \cdot \mathrm{min}^{-1}$ under nitrogen atmosphere.

observed in Figure 1, indicating the bonding of PMA monomers with PHSSO. The FTIR result suggests that the methacrylate group is successfully incorporated into the PHSSO.

The number-average molecular weight $\left(\bar{M}_{n}\right)$ of the PHSSO precursor was 5030 with the polydispersity index of 1.82 and the ratio of cage-like/network-like structures was 3.2. If the size of cage-like and network-like structures is assumed to be similar, the diameter of PHSSO could be estimated to be $11 \mathrm{~nm}$ based on the ratio of $\bar{M}_{\mathrm{n}}$ of PHSSO and $\left(\mathrm{SiO}_{1.5}\right)_{8}$. After hydrosilylation, the $\bar{M}_{\mathrm{n}}$ of the PHSSO-PMA precursor was 12280 with the polydispersity index of 2.69. The hydrosilylation ratio estimated by TGA was about $48 \%$ by the 1:0.8 loading mole ratio of SiH:PMA in the present study. That means the side group of the PHSSO-PMA contained $48 \%$ of PMA and $52 \%$ of $\mathrm{Si}-\mathrm{H}$ moieties. We also attempted other loading ratio at the low loading ratio of 1:0.3 for Si-H/PMA but the gelation would have occurred due to the intramolecular hydrosilylation reaction. ${ }^{[\mathrm{bb}]}$ However, if the high mole ratio of PMA/Si-H (e.g., 1:1) was used, the hydrosilation ratio was not increased but was with a large PMA residue. Hence, the PHSSO-PMA precursor prepared from the hydrosilation reaction with the SiH:PMA mole ratio of 1:0.8 was used for preparing hybrid materials.

Three kinds of acrylate functional monomers with different weight ratios are used to prepare hybrid materials with PHSSO-PMA, PHSSO-PMA/BzMA (P1), PHSSO-PMA/BAEDA(P2), and PHSSO-PMA/TMPTA/BzMA (P3). As shown in Figure 1, the intensity of $1640 \mathrm{~cm}^{-1}(C=C$ of methacrylate group) of the hybrid materials, P1-30, P2-30, and P3-30 is almost disappeared after UV irradiation and thermal curing, implying the nearly complete polymerization of the hybrid materials. Hence, the prepared hybrid materials could be used for photopatterning device applications.

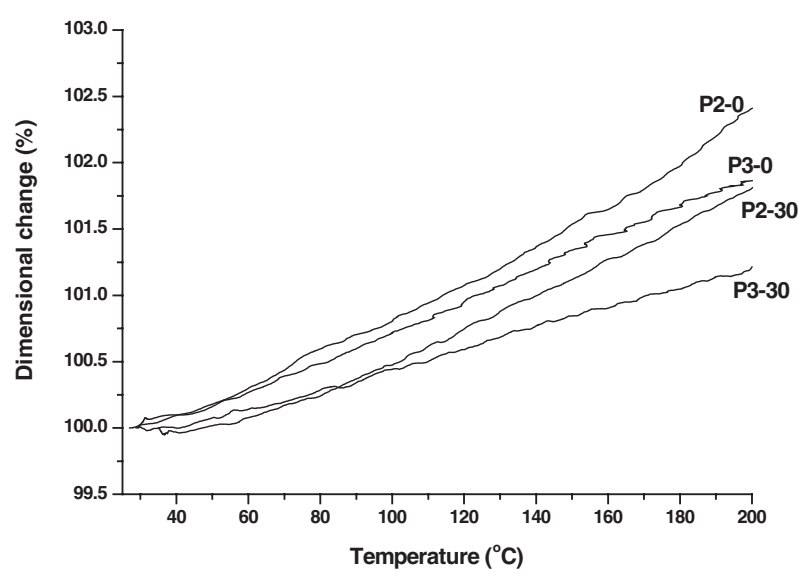

Figure 3. TMA curves of P2-0, P2-30, P3-0, and P3-30, respectively.

\section{Properties of the Hybrid Materials}

Figure 2 shows the TGA curves of P1-0, P1-30, P2-0, P2-30, P3-0, and P3-30 under nitrogen atmosphere at the heating rate of $10^{\circ} \mathrm{C} \cdot \mathrm{min}^{-1}$, respectively. Note that the $\mathbf{P 1 - 0 , ~} \mathbf{P 2 - 0}$, and $\mathbf{P 3 - 0}$ are the parent polymers of poly(benzyl methacrylate), poly(bisphenol A ethoxylate diacrylate), and poly[(trimethylolpropane triacrylate)-co-(benzyl methacrylate)], respectively. As shown in the figure, the hybrid materials have a slightly higher thermal decomposition temperature but a much higher char yield than their parent polymers. The thermal decomposition temperatures as well as other physical properties of the studied materials are summarized in Table 1. Figure 3 shows the TMA curves of P2-0, P2-30, P3-0, and P3-30, respectively, in which the CTE are 151, 118, 128, $76 \mathrm{ppm} \cdot{ }^{\circ} \mathrm{C}^{-1}$, respectively. It suggests that the CTE could be significantly reduced by incorporating the PHSSO-PMA. The CTE of the other hybrid materials shown in Table 1 also suggests a similar trend. It suggests that the extensive crosslinking and incorporating nano-size silsesquioxane structures are the major factors contributing to the dimensional stability of the hybrid films.

The film thickness measured by prism coupler are in the range of 1.03-1.75, 11.36-14.41, and 7.68-11.35 $\mu \mathrm{m}$, for the P1, P2, and P3 hybrid materials, respectively. The molecular weight and viscosity of the BAEDA moiety are higher than the other two acrylate monomers and thus the film thickness of $\mathbf{P 3}$ is higher than those of $\mathbf{P 1}$ and $\mathbf{P 2}$. Besides, the film thickness of $\mathbf{P} \mathbf{1}$ could not be over $2 \mu \mathrm{m}$ due to the low molecular weight and viscosity of BzMA. Figure 4 shows the AFM images for the waveguide films P2-30 and P3-30, respectively. The average roughness $\left(R_{\mathrm{a}}\right)$ for P2-30 and P3-30 is 1.33 and $0.53 \mathrm{~nm}$, respectively, while the mean square roughness $\left(R_{\mathrm{q}}\right)$ is 1.68 and $0.68 \mathrm{~nm}$. The relatively low surface roughness in comparison with the 


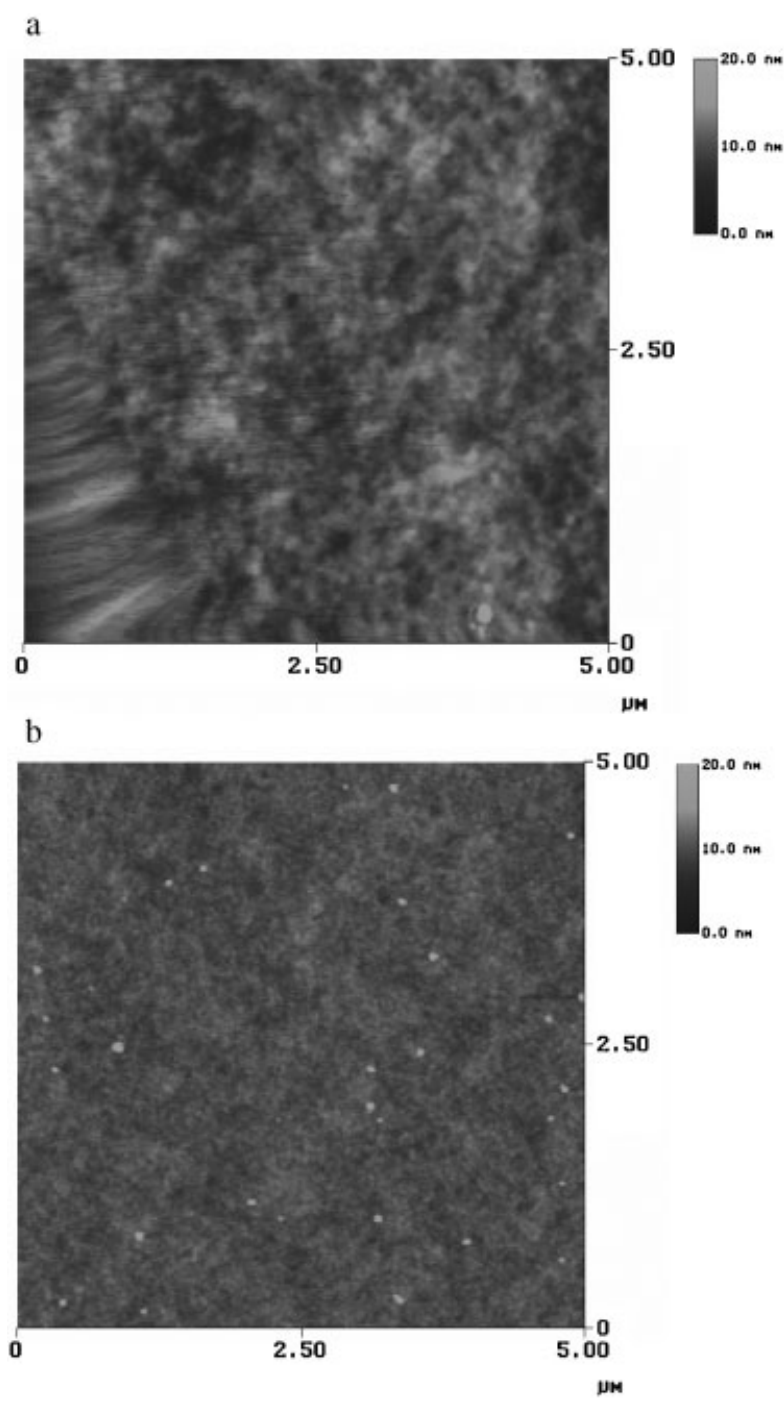

Figure 4. AFM images of the prepared hybrid films on the silicon wafers: (a) P2-30 and (b) P3-30.

corresponding film thickness suggests the uniform hybrid films. The SEM images of the hybrid materials also do not show any significant domain size, indicating uniform film quality of the hybrid materials.

Figure 5 shows the UV-vis absorption spectra of PHSSO-PMA, P1-30, P2-30, and P3-30, which exhibit high transparency in the wavelength range of 400-1000 nm. The relatively small silsesquioxane domain and chemical bonding between the organic and inorganic moiety prevent phase separation and thus explain the excellent optical quality of the prepared hybrid films. The refractive index at $1310 \mathrm{~nm}$ is also similar, 1.561-1.536 and 1.508-1.494, for the P2-0-P2-40 and P3-0-P3-40, as shown in Table 1 . The refractive index of the hybrid film is decreased as the content of the PHSSO (or) silsesquioxane is enhanced, which is due to the low refractive index of the PHSSO $(n=1.402)$ measured by the prism coupler. ${ }^{[21 g]}$ The

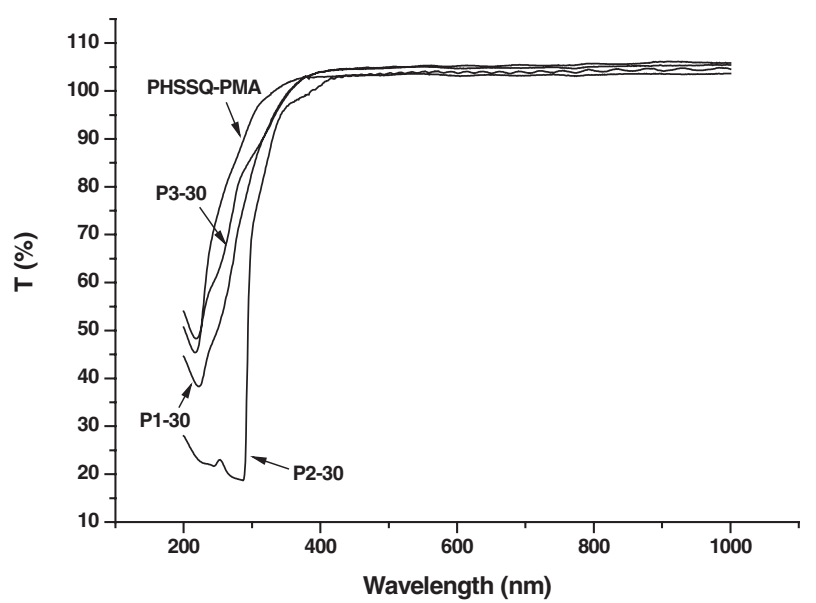

Figure 5. UV-visible transmission spectra of the prepared hybrid films on quartz substrates: PHSSO-PMA, P1-30, P2-30, and P3-30.

refractive index would be decreased with an increase in the amount of the PHSSO since it created the free volume in the hybrid materials due to its cage-like structure. It explains the low refractive index of the silsesquioxanebased hybrid materials.

The film thickness of the $\mathbf{P 1 - 0} \sim \mathbf{P 1 - 7 5}$ hybrid materials is too thin for preparing optical waveguide and thus the waveguide characteristics of the other two kinds of hybrid materials are reported. The multimode planar waveguides were fabricated with the structures of the hybrid films on top of the thermal oxide (refractive index $=1.447$ ) using silicon wafers as the substrate. The cut-back method was used previously by our laboratories to determine the propagation optical losses at $1310 \mathrm{~nm} .^{[22 \mathrm{~b}, 22 \mathrm{c}]}$ Figure 6 shows the variations of transmitted optical power $(-10$ $\log P$ ) with the lengths for the hybrid materials of $\mathbf{P 2 - 0}$, P2-40, P3-0, and P3-40, respectively. The estimated optical losses of the above four materials are $0.68,0.43,0.58$, and $0.29 \mathrm{~dB} \cdot \mathrm{cm}^{-1}$, respectively, while those of the other hybrid materials are listed in Table 1 . The comparison on optical losses of the P3 hybrid materials suggests that the incorporation of the PHSSO-PMA could reduce the optical loss. For pure organic polymer-based optical waveguides reported in the literature, polyguides (acrylic-based polymer) could achieve optical losses of $0.2 \mathrm{~dB} \cdot \mathrm{cm}^{-1}$ at $1310 \mathrm{~nm}$. Other kinds of polymers could even achieve much lower values. ${ }^{[25,26]}$ As discussed previously, the hybrid materials have the nano-size silsesquioxane domain and uniform film quality and thus scattering loss is insignificant in the film. Besides, the incorporation of the PHSSO could reduce the $\mathrm{C}-\mathrm{H}$ number density and thus the optical loss is decreased. Note that the optical loss of pure organic polymers is mostly originated from the $\mathrm{C}-\mathrm{H}$ number density. ${ }^{[21,22 b, 22 c, 25]}$ Figure 7 shows the near infrared absorption spectra of P3-0, P3-20, and P3-40. The absorption bands in the range of 1120-1260 and 




Figure 6. Variation on transmitted optical power with the lengths of the prepared waveguide films, P2-0, P2-40, P3-0, and P3-40, respectively.

1600-1 $850 \mathrm{~nm}$ are assigned to be the third $\left(v_{3}\right)$ and second $\left(v_{2}\right)$ harmonic stretching vibration absorption bands of the $\mathrm{C}-\mathrm{H}$ bond. The absorption band in the range of 1320$1530 \mathrm{~nm}$ results from a combination of the second harmonic stretching vibration $\left(v_{2}\right)$, the bending vibration $(\delta)$ of the $\mathrm{C}-\mathrm{H}$ bond and the second harmonic stretching vibration of $\mathrm{OH}$ bond $\left(v_{2}\right)$. Hence, the intrinsic absorption loss at $1310 \mathrm{~nm}$ is mostly from $\mathrm{C}-\mathrm{H}$ vibration absorption and the $\mathrm{C}-\mathrm{H}$ bonding density could be decreased with an increase in PHSSO content. The smaller intensities of these absorption bands in P3-40 than those of P3-0 are probably due to the reduction of $\mathrm{C}-\mathrm{H}$ number density as explained above. In the case of the $\mathbf{P 2}$ hybrid materials, the correlation between the optical loss at $1310 \mathrm{~nm}$ with the PHSSO content is not as clear as that of the P3 although the optical loss of $\mathbf{P 2 - 4 0}$ is significantly lower than that of P2-0. The interface between the hybrid materials and the thermal oxide could result in such an unexpected trend.

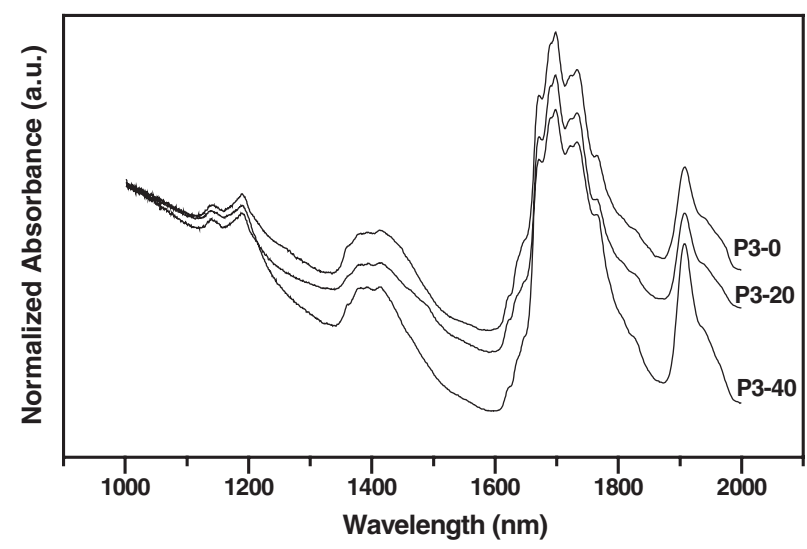

Figure 7. Near infrared absorption spectra of P3-0, P3-20, and P3-40 bulk sample in the wavelength range of 1000-2000 nm. a

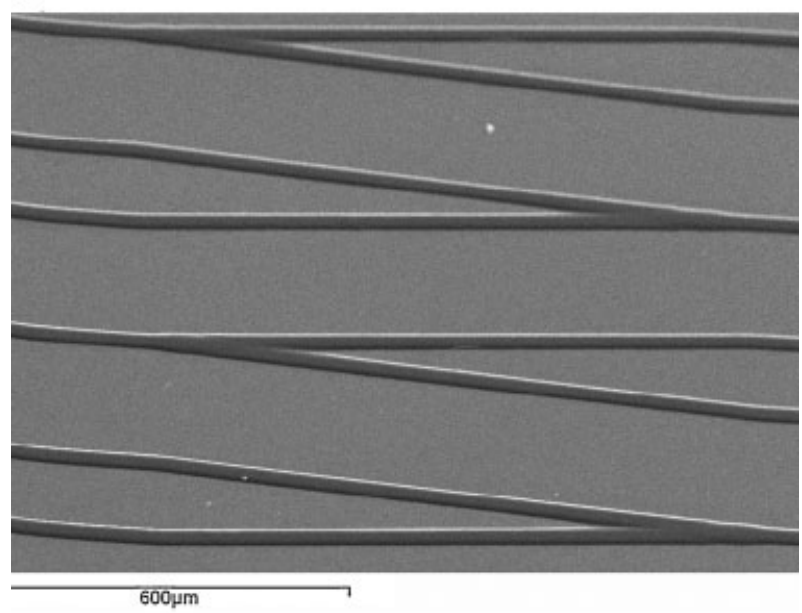

b



Figure 8. SEM images of the developed patterns with $10 \mu \mathrm{m}$ line width and a $10^{\circ}$ splitting angle, left: P2-40; right: P3-40.

Figure 8 shows the SEM diagrams of the developed patterns of P2-40 and P3-40 with $10 \mu \mathrm{m}$ width, $1.5 \mu \mathrm{m}$ thickness, and $10^{\circ}$ splitting angle. Both P2-40 and P3-40 show clear developed patterns. Based on the optical properties and patterning resolution, the prepared hybrid materials could have potential applications for patterned optical devices. The present study demonstrates that the incorporation of silsesquioxane domain could not only significantly enhance the thermomechanical properties but also enhance the optical characteristics.

\section{Conclusion}

We have successfully synthesized three series of new acrylic/silsesquioxane hybrid materials through the precursor of methacrylate-functionalized PHSSO. By incorporating the nano-size silsesquioxane moiety, the thermomechanical properties of the parent acrylic polymers could 
be significantly enhanced. Besides, the refractive index and optical loss were reduced by such moiety. Relatively low optical loss of $0.29 \mathrm{~dB} \cdot \mathrm{cm}^{-1}$ at $1310 \mathrm{~nm}$ was obtained with the PHSSO-PMA/TMPTA/BzMA hybrid material-based optical waveguide. The hybrid materials could be photocured to develop Y-shaped pattern with $10 \mu \mathrm{m}$ line width and a $10^{\circ}$ splitting angle. The newly prepared photocurable hybrid materials could have the potential applications for patterned electronic and optoelectronic devices.

Acknowledgements: We thank the financial supports from National Science Council of Taiwan, Ministry of Economics Affairs of Taiwan, and Industrial Technology Research Institute.

Received: November 16, 2006; Revised: February 1, 2007; Accepted: February 21, 2007; DOI: 10.1002/mame.200600442

Keywords: composites; hybrid; optical films; photopolymerization; silsesquioxane

[1] C. Sanchez, B. Lebeau, MRS Bull. 2001, 26, 377.

[2] C. R. Kagan, D. B. Mitzi, Science 1999, 286, 945.

[3] W. U. Huynh, J. J. Dittmer, A. P. Alivisatos, Science 2002, 295, 2425.

[4] N. Tessler, V. Medveder, M. Kazes, S. Kan, U. Banin, Science 2002, 295, 1506.

[5] [5a] L. H. Lee, W. C. Chen, Chem. Mater. 2001, 11, 1137; [5b] C. C. Chang, W. C. Chen, Chem. Mater. 2002, 12, 4242; [5c] C. Y. Yen, W. C. Chen, D. J. Liaw, H. Y. Lu, Polymer. 2003, 44 7079; [5d] W. J. Lin, W. C. Chen, W. C. Wu, Y. H. Niu, A. K. Y. Jen, Macromolecules 2004, 37, 2335; [5e] Y. W. Wang, C. T. Yen, W. C. Chen, Polymer 2005, 46, 6959.

[6] [6a] R. H. Baney, M. Itoh, A. Sakakibara, T. Suzuki, Chem. Rev. 1995, 95, 1409; [6b] D. A. Loy, B. M. Baugher, C. R. Baugher, D. A. Schneider, K. Rahimian, Chem. Mater. 2000, 12, 3624; [6c] R. M. Laine, J. Mater. Chem. 2005, 15, 3725; [6d] T. Masuda, S. Yamamoto, O. Moriya, M. Kashio, T. Sugizaki, Polym. J. 2007, 39, 220.

[7] [7a] J. D. Lichtenhan, Y. A. Otonari, M. J. Carr, Macromolecules 1995, 28, 8435; [7b] A. Sellinger, Macromolecules 1996, 29 , 2327; [7c] R. O. R. Costa, W. L. Vasconcelos, R. Tamaki, R. M. Laine, Macromolecules 2001, 34, 5398.

[8] J. Choi, J. Harcup, A. F. Yee, J. Am. Chem. Soc. 2001, 123, 11420.
[9] J. Choi, A. F. Yee, R. M. Laine, Macromolecules 2003, 36, 5666.

[10] Y. Ni, S. Zheng, Macromol. Chem. Phys. 2005, 206, 1075.

[11] G. M. Kim, H. Qin, X. Fang, F. C. Sun, P. T. Mather, J. Polym. Sci., Part B: Polym. Phys. 2003, 41, 3299.

[12] M. J. Abad, L. Barral, D. Fasce, R. J. J. Williams, Macromolecules 2003, 36, 3128.

[13] L. H. Lee, W. C. Chen, Polymer 2005, 46, 2163.

[14] R. Tamaki, Y. Tanaka, M. Z. Asuncion, J. Choi, R. M. Laine, J. Am. Chem. Soc. 2001, 123, 12416.

[15] C. M. Leu, Y. T. Chang, K. H. Wei, Macromolecules 2003, 36 9122.

[16] T. H. Lee, J. K. Kim, B. S. Bae, J. Mater. Chem. 2006, 16 1657.

[17] C. Zhang, F. Babonneau, C. Bonhomme, R. M. Laine, C. L. Soles, H. A. Hristov, A. F. Yee, J. Am. Chem. Soc. 1998, 120, 8380.

[18] D. Neumann, M. Fisher, L. Tran, J. G. Matisons, J. Am. Chem. Soc. 2002, 124, 13998.

[19] K. M. Kim, D. K. Keum, Y. Chujo, Macromolecules 2003, 36, 867.

[20] G. S. Constable, A. J. Lesser, E. B. Coughlin, Macromolecules 2004, 37, 1276.

[21] [21a] W. C. Chen, C. T. Yen, J. Polym. Res. 1999, 6, 197; [21b] W. C. Chen, S. C. Lin, B. T. Dai, M. S. Tsai, J. Electrochem. Soc. 1999, 146, 3004; [21c] W. C. Chen, C. T. Yen, J. Vac. Sci. Technol. B 2000, 18, 201; [21d] W. C. Liu, C. C. Yang, W. C. Chen, B. T. Dai, M. S. Tsai, J. Non-Cryst. Solids 2002, 311, 233; [21e] C. C. Yang, W. C. Che, J. Mater. Chem. 2002, 12, 1138; [21f] L. H. Lee, W. C. Chen, W. C. Liu, J. Polym. Sci., Part A: Polym. Chem. 2002, 40, 1560; [21g] W. C. Liu, Y. Y. Yu, W. C. Chen, J. Appl. Polym. Sci. 2004, 91, 2653.

[22] [22a] T. Watanabe, N. Ooba, S. Hayashida, T. Kurihara, S. Imamura, J. Lightwave Technol. 1998, 16, 1049; [22b] W. C. Chen, L. H. Lee, B. F. Chen, C. T. Yen, J. Mater. Chem. 2002, 12, 3644; [22c] W. C. Chen, W. C. Liu, P. T. Wu, P. F. Chen, Mater. Chem. Phys. 2004, 83, 71.

[23] [23a] C. H. Chou, S. L. Hsu, K. Dinakaran, M. Y. Chiu, K. W. Wei, Macromolecules 2005, 38, 745; [23b] C. M. Brick, Y. Ouchi, Y. Chujo, R. M. Laine, Macromolecules 2005, 38, 4661; [23c] Y. Xiao, L. Liu, C. He, W. S. Chin, T. Lin, K. Y. Mya, J. Huang, X. Lu, J. Mater. Chem. 2006, 16, 829; [23d] H. J. Cho, D. H. Hwang, J. I. Lee, Y. K. Jung, J. H. Park, J. Lee, S. K. Lee, H. K. Shim, Chem. Mater. 2006, 18, 3780.

[24] [24a] Y. Ni, S. Zheng, Chem. Mater. 2004, 16, 5141; [24b] H. M. Lin, S. Y. Wu, P. Y. Huang, C. F. Huang, S. W. Kuo, F. C. Huang, Macromol. Rapid Commun. 2006, 27, 1550.

[25] H. Ma, A. K. Y. Jen, L. R. Dalton, Adv. Mater. 2002, 14, 1339.

[26] L. Eldada, L. W. Shacklette, IEEE J. Sel. Top. Quantum Electron. $2000,6,54$. 